\title{
NAVAL AND MILITARY SURGERY.
}

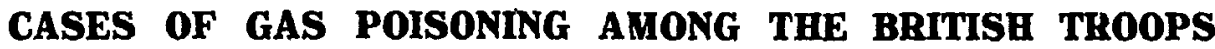 IN FLANDERS.}

By Col. Sir JOHN ROSE BRADFORD, K.C.M.G., C.B., F.R.S., A.M.S., and CAPT. T. R. ELLIOTT, F.R.S., R.A.M.C.

AT the date when these notes were written-namely, the last week of Junethere had been three chief attacks made on the English lines by the enemy under cover of asphyxiating gases. The first took place on April 23 and 24, immediately to the north of Ypres. The day before this, gas had suddenly been poured upon a sector of the French line adjoining the left of the British, and the stifling fumes were so unexpected that the Algerian and Zouave defence broke before them. Warned by this, but otherwise unprepared, the Canadian troops and various English units had to face similar attacks on the following days. No respirators were available. The nature of the gas and its later effects on the men were entirely unknown. The troops held their ground, but the losses were heavy.

From May 2 to May 5 a second attack with gas was made south of Ypres. Pad respirators, moistened with a solution of bicarbonate of soda, had now been improvised, and these gave the men some slight protection.

The third attack was on, May 24. By this time much better respirators were available, and the sufferings of the men were correspondingly less.

In addition to the trench gas, which is supposed to be emitted from cylinders, and has been proved by various indirect tests to consist chiefly of chlorine, the Germans have employed special asphyxiating shells, which contain other substances that cause more direct stupefaction, or are more directly irritating to the eyes and produce a temporary blindness. Their nature is not fully known, but organic compounds of bromine have been identified among them.

The following account deals only with the results of exposure to the trench gas, and chiefly it describes the condition of the soldiers who suffered from the poisoning in its acutest form before the use of adequate respirators. The symptoms may be grouped under three headings, according as they are caused by $(a)$ irritation of the respiratory tract, (b) gastric irritation, (c) a general toxic action.

Death is liable to occur at any one of three successive stages of injury produced by the poison-namely: (1) In the first few hours on the field, the patient then presenting a greenish-yellow aspect, like that of asphyxia pallida. This is apparently the result of direct poisoning; (2) Up to the fourth or 
fift day, when the man is overwhelmed by a livid asphyxia due to œedema and disruptive emphysema of the lungs; (3) Later, at any time up to the end of the second week, from inflammatory complications, such as purulent bronchitis or bronchopneumonia, with pleurisy and heart failure. Only one death has been rccorded at the end of the third week, and that was from generalized emphysema with heart failure.

I. On the Field.-All the men gave the same description of what they felt as the greenish-yellow fumes enveloped them. Choking, coughing, gasping for breath, and inability to speak, proved the irritation and spasm of the respiratory tract. In many the eves smarted and ran with water. Very soon the toxic effects of the gas showed themselves in headache, with a sense of weakness in the legs, and such lassitude that the men dropped prone upon the ground, the spasmodic violence of their respiratory efforts being largely quietened. In this posture they lay in still greater danger, since the heavy gas clung in more poisonous concentration to the trench bottoms and recesses of the ground. The throat burned, and the dry mouth produced an intense sensation of thirst. Retching was at once experienced by some, but many did not vomit until an hour or two later, when a draught of water caused yellowish fluid to be brought up, with a considerable sense of relief. Irritation of the trachea resulted in severe pain behind the sternum, which soon radiated outwards on each side into the chest, and added greater suffering to the distressed breathing.

Stumbling through the gun-fire, and half stupefied, most of the men reached shelter and medical aid behind the trenches, where many of them lapsed into a-state of semi-consciousness. Those who died on the field were greenish-white in the face, not blue. death.

No post-mortem examination has been made on any such case of early

2. Second. to Fifth Day.-Consciousness was now, as a rule, restored. The vomiting and the violent cough had ceased. The appearances presented by the most severe cases were those of the deepest asphyxia. The congested face was of a violet-red colour, the ears and finger-nails livid. The arteries were distended, with a full pulse at a rate of less than 100 . The breathing was shallow and extraordinarily rapid, up to 60 or even 80 in the minute; but the movements were effected chiefly by the diaphragm and accessory muscles at the upper inlet, the chest itself being held in a position of utmost distention. Everywhere the percussion note was resonant, even over the bases, which autopsy proved to be almost solid with oedema; and the breath sounds were harsh, and accompanied by numerous fine crepitant râles. In the first day there was a profuse expectoration of a yellow, highly albuminous fluid, which was sometimes so abundant that it ran from the patient's mouth when the stretcher was tilted head downwards. Later this subsided, and was replaced by a viscous primrose-yellow sputum; - which was often streaked with blood from tracheal hæmorrhages, or stained reddish-brown when it came from infarcted areas within the lung.

Despite this hurried breathing, the sufferer complained more of pain in 
the throat, chest, and epigastrium than of shortness of breath ; and he preferred to sink down in the bed rather than sustain the effort of sitting propped up. The lips were parched, the roof of the mouth.glazed, and the tongue so heavily coated with a brown, dried fur that several patients repeatedly scratched the inside of their mouths with their finger-nails to remove the "leathery gluey feeling." No abnormal odour was noticed in the breath. There was frequent and shallow, but painful, cough. The temperature was raised to $100^{\circ}$ or $101^{\circ}$, but the skin was dry, unlike the general state of steaming perspiration which accompanies the occasional asphyxiation of ordinary bronchitis.

Many died at this stage. Autopsy revealed the ordinary features of an asphyxial death, but with two peculiar changes in the lungs as the cause of this asphyxiation. They are disruptive emphysema and generalized oedema.

Fig. 75.-Drawing of the trachea of a patient who died thirty-six hours after having been gassed. He was deeply cyanosed, and lightly delirious. In the actual specimen the most striking feature was the abrupt line of transition $(T)$ from the purple plum-coloured mucous membrane of the upper pharynx to the healthy pinkish-white tint of the unaffected cesophagus at the level of the thyroid cartilage. All the surfaces over which the irritant gas played are deeply injected and discoloured. There was, however, very little cedema in the trachea, and no inflammatory membranes had been formed.

Curiously, the laryngeal aperture was in most cases free from odema and irritation. The voice rarely became hoarse, and the dyspncea, at any rate after the first few hours, was never caused by laryngeal obstruction. This extreme congestive irritation was evident in almost all the fatal cases before the use of respirators. The protection devised later prevented this injury of the pharynx and trachea, even in men who died with inflammatory odema of the more delicate lung tissues. [Ref. No. 5.]

The one bursts the alveoli, the other fills them with albuminous inflammatory exudate. Circulation of the blood through the lungs is consequently hindered, and the gaseous exchange arrested in the areas affected. Death is the result of the physical changes produced by the respiratory irritant-namely, the violent cough and spasm with its disruptive emphysema, and the later inflammatory cedema.

If the patient survived the asphyxiation of the first few days, his colour soon became normal again; but the dyspnoea persisted for some time, and a cyanotic tinge at once returned to the face when any muscular efforts were made. Mr. J. Barcroft, F.R.S., analysed the blood of several sufferers in an investigation as to whether this prolonged dyspnoea might be due to a special acidosis from an inhaled poison. Nothing was found beyond the ordinary changes due to diminished oxygen intake and carbon dioxide output: so it is probable that the dyspnca was due partly to emphysema and partly to the 


\section{NAVAL AND MILITARY SURGERY 237}

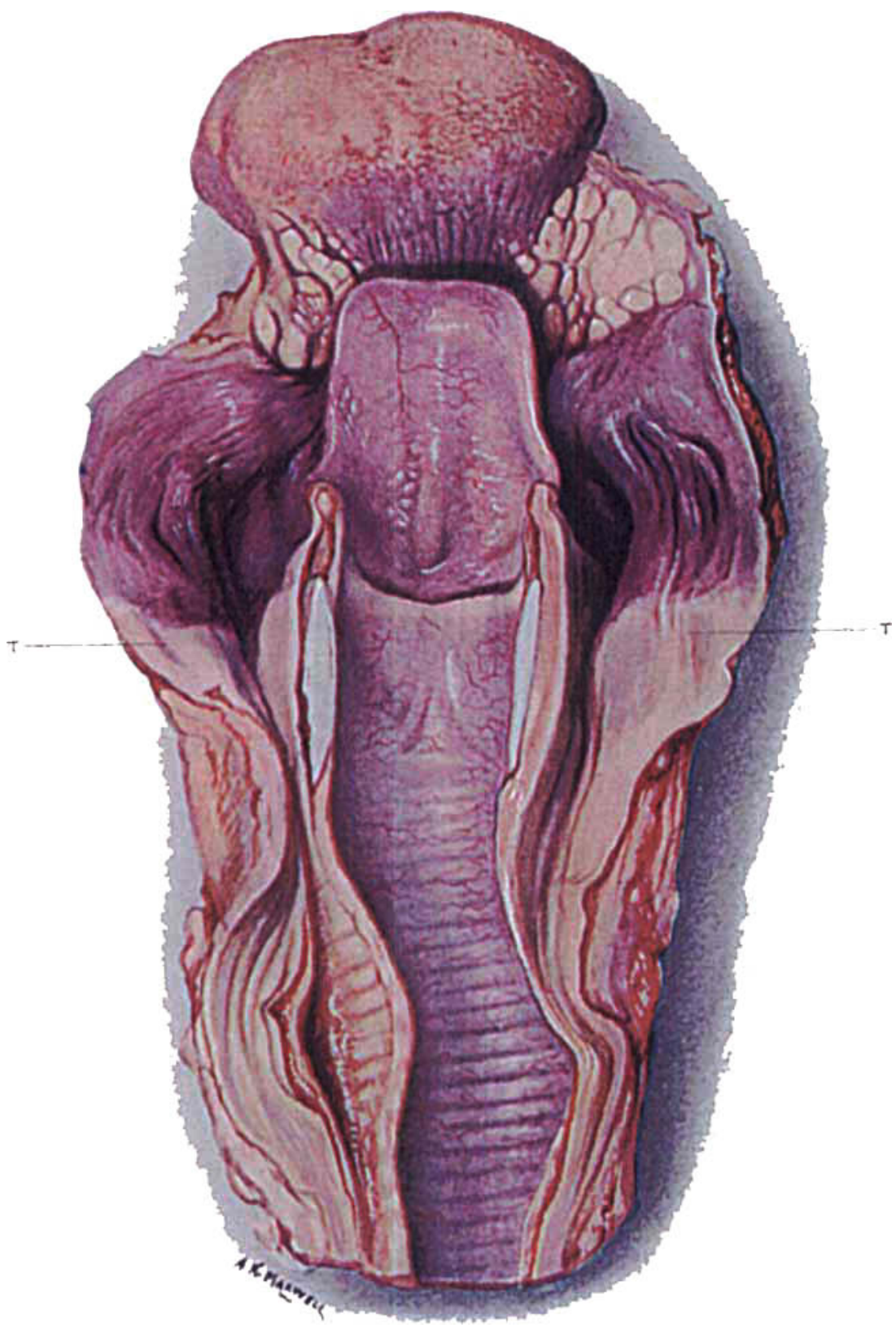

Fig. 75.--Drawing of the Trachea of a Patient who died thitex-bix hours after beina Gassrid.

$T$. Note the abrupt line of transition in colour from purple to healthy tint, at the level of the trachea. 
persistence of œdematous areas in the depths of the lungs, leaving a small respiratory surface which could suffice only for the gaseous exchanges of the body while at rest.

The râles vanished in a few days, and the patient then complaincd only of headache, lassitude, and occasionally epistaxis if he got up too carly. Dyspnoca was not obvious in the later convalescence.

\section{Later Period of Inflammatory Complications in the Lungs.-} These complications were more frequent and fatal in those gassed bcfore the use of respirators. As they developed, the temperature rose again, and the sputum became purulent, sometimes blood-stained, and often abundant and nummular, but inoffensive. A fine pleurisy could generally be detected on one side or the other, the cedematous râles persisted. and to these were added rhonchi in all the tubes, and the breath sounds of imperfectly consolidated lung, though never of frank lobar pneumonia. The cyanosis persisted, and the pulse often indicated progressive weakening of the heart. Some of these

Fig. 76.-Congested kidney from the same patient as shown in the previous figure. The drawing does not give the full cyanotic tint of the actual specimen, but the congested vessels are satisfactorily shown. Fven in this early case there is a tendency to a yellowish appearance in the cortex, which foreshadows the very obvious features of parenchymatous nephritis that are established in men who die in the second week. A description of such a later specimen will be found in Lieut. Henry's memorandum. [Ref. No. 4.]

cases died in the second week, but all who survived bevond that recovered-at any rate. from the acute illness.

Out of 25 men of the 15th Canadian Battalion (Montrcal Highlanders) who were seen at Bonlogne after having becn gassed on April 24. 3 died in the carly stages fron asphyxia, 3 from late bronchitis and bronchopneumonia in the second weck, and 4 severe cases with sccondary infections recovered. These figures, however, give an exaggerated idca of the fatality. The total mortality was probably under 10 per cent, and of the patients who survived to reach the base hospitals and yet were ill enough to be sent down, less than 2 per cent died. The actual figures have not yet been published by the army medical authorities.

The pulmonary lesions and the asphyxial hremorrhages constitute the chicf clinical and pathological features in men who have been poisoned by trench gas. Some other points, however, descrve mention. The poison is absorbed into the circulation, through which it affects the nervous system, the kidneys, and probably the stomach.

In many cases the stomach after death showed multiple petechial hæmorrhages, or even areas of wider crosion. Probably these were not altogether 


\section{NATAL AND MILITARY SURGERY 239}

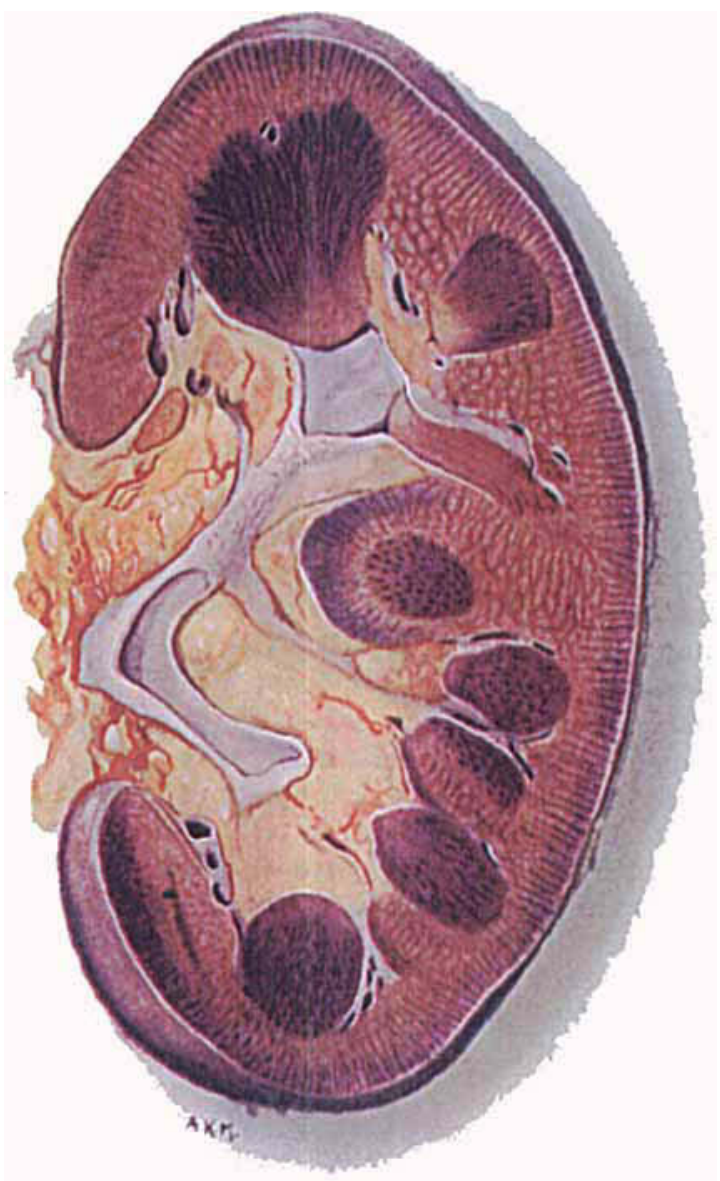

Fio. 76.-Congested Kidney prox the saye Patient as shown in Fig. 75. 
asphyxial, but were caused by the action of the gastric juice on a mucous membrane the vitality of which had been lowered by the circulating poison. Epigastric pain was often complained of by the men, and in some cases it was aggravated by solid food. Hæmatcmesis was never observed, but in two out of sixteen autopsies the stomach was found to be full of blood.

Headache and fatigue were evidence of the poisoning of the central nervous system. The ordinary gas did not produce lasting coma. No physical signs were found to indicate localized lesions in the central nervous system, and there was no instance of peripheral neuritis. Naked-eye examination after death revealed no changes in the brain other than those of asphyxia.

Fig. 77.-Drawing of a foot with vascular obstruction caused by gas poisoning. The clinical details were as follows :-

April 24.-The patient was gassed at daybreak. He was in dry trenches, under conditions which could not possibly have induced anything resembling frost-bite.

April 27.-Admitted to hospital at Boulogne. Pulse 90. Breathing painful and rapid, 50 to the minute. Lungs full of fine râles." Face slightly cyanosed, and terminal inch of nose livid and cold. Right hand slightly mottled, cold, and painful. Both feet stone cold and discoloured. No pulsation could be felt in the dorsalis pedis artery. Immediately above the ankle vital warmth commenced, and there was slight œdema, with so much tenderness and pain that the patient could not endure the pressure of the bed-clothes on his feet. The feet themselves were quite anæsthetic. The urine contained a trace of albumin, but no sugar.

May 2.-Purulent bronchitis. Temperature $104^{\circ}$, respirations 36. Nose and hand normal. Feet warm, but the toes were zold and much blacker, while the area around the ankles was redder and more cedematous.

May 17.-Practically well. Discharged to England. Feet almost normal, except that a couple of toes were black and shrivelled, suggesting that the superficial tissues would ultimately separate with a dry gangrene. The condition was very like that of Raynaud's disease, but the patient had never suffered from that ailment. [Ref. No. 2.]

The hæmoglobin and plasma of the blood had lost none of their respiratory properties; but owing to the uselessness of the lungs the blood was asphyxial, and clotted very rapidly after death. Three patients, none of whom died, dcveloped a vascular obstruction in their extremities, with progressive loss of the arterial pulse. The onset of this was slow, and not of an embolic character. The limb became cold and livid, presenting an appearance very much like that seen in some cases of frost-bite. Gangrene at first seemed likely, but the circulation was soon restored and the tissues regained their vitality. In the case related below, from which the drawing of Fig. 77 was made, the symmetrical distribution of the vascular changes proved that they could not have been simple pressure effects caused at the time when the man may have lain out in a semi-conscious state. 


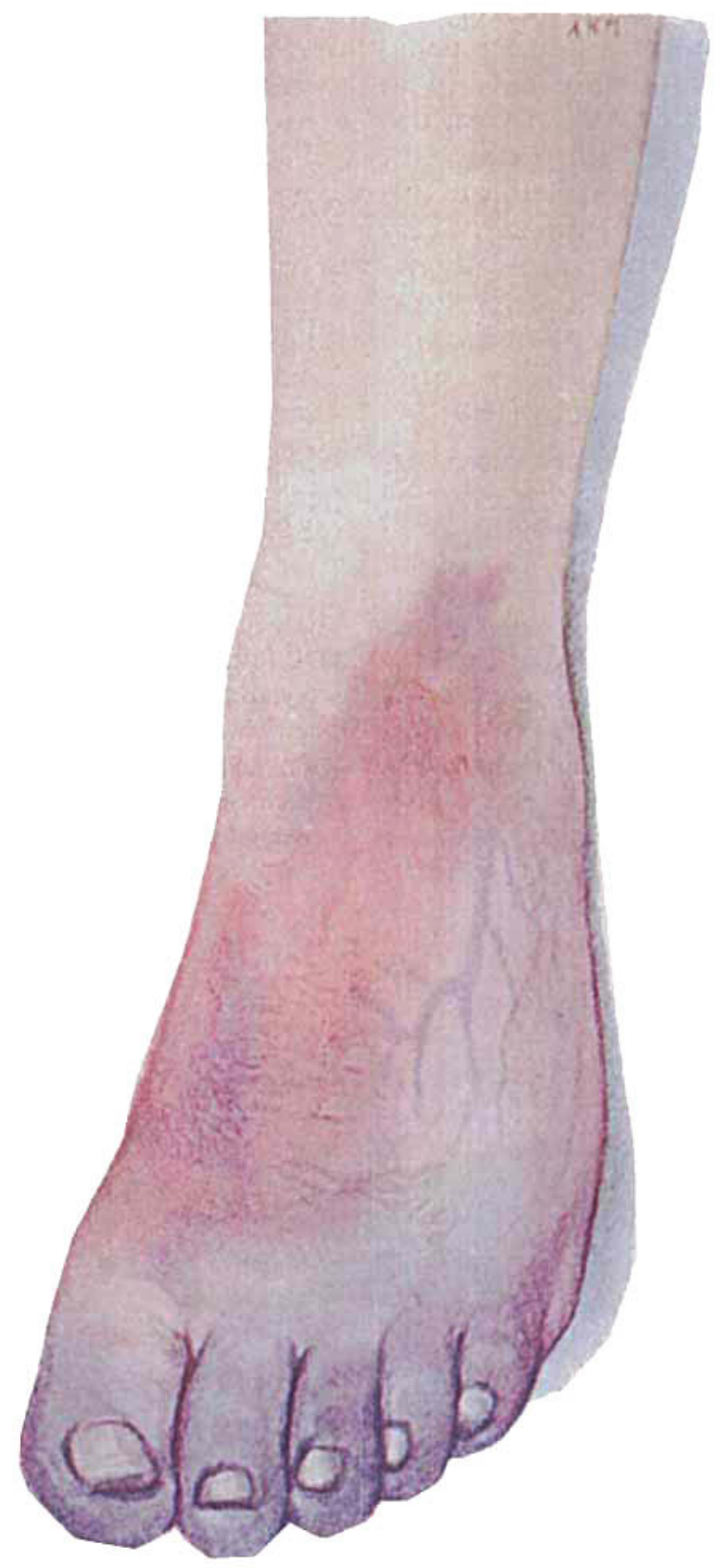

Fia. 77.-Dinateg of the Foot of a Patiest showing Vascular Obstruction, tile Effect of Gas Poisonino. 
The kidney lesions are of great pathological interest, but fortunately they do not appear conspicuously in the clinical picture. In all men who died in the second week, the kidneys showed the changes of a moderate acute parenchymatous nephritis, being pale and swollen. The first stage of such a nephritis could also be detected in cases of death during the first few days, when the kidney, in addition to venous congestion, showed a yellowish tint in the cortex that is slightly exaggerated in Fig. 76. Microscopic examination revealed a tubal nephritis in all, with changes also in the glomeruli. Yet none of them in life had oedema; only one showed uramic symptoms; and the urine in gassed cases generally was remarkably free from albumin and casts. It remains for further study of the history of these men to determine whether such a toxic nephritis, that at its incidence is clinically so unobtrusive, is likely at a later date to cause degenerative changes in the organ. If such were the unfortunate sequel, the example would be of interest in its relationship to the general question of the etiology of chronic nephritis in civil life.

With this reservation, the prospect of a complete recovery for men who

Fig. 78.-Lung of a patient who died four days after having been gassed. Disruptive emphysema was relatively slight in this case, and there was no mediastinal emphysema. The upper drawing shows scattered subpleural hæmorrhages. The lobular reticulation marks the lines along which air-bubbles are found in the emphysematous cases. The Iungs were voluminous and almost solid with cedema, so that they presented a uniformly fleshy appearance on section. From the trachea exuded a frothy serum, which was congealed to a yellowish white friable mass by the formalin preservative. [Ref. No. 3.]

have been badly gassed, but survived the first fortnight's illness, seems to be good.: Disruptive emphysema, it must be admitted; damages the lung tissue to an extent which, in those who have died, seems almost irreparable. But it is probable that this injury is of a much less severe nature in the men who survived. Chronic emphysematous changes may make their appearance in them later, but no such unusual shortness of breath was noticed in the convalescents as would make one very apprehensive of this disability.

\section{NOTES ON THE POST-MORTEM FINDINGS IN SIXTEEN CASES.}

\section{(By Lieut. Herbert Henky, R.A.M.C.)}

The description herein briefly outlined of the post-mortem findings in death from gas poisoning, embodies observations made on a series of sixteen cases which died in hospitals at the Boulogne base. It is well at the outset to bear in mind that the description is not only an incomplete one by reason of the limited material available, but that it is also one-sided, for it deals 


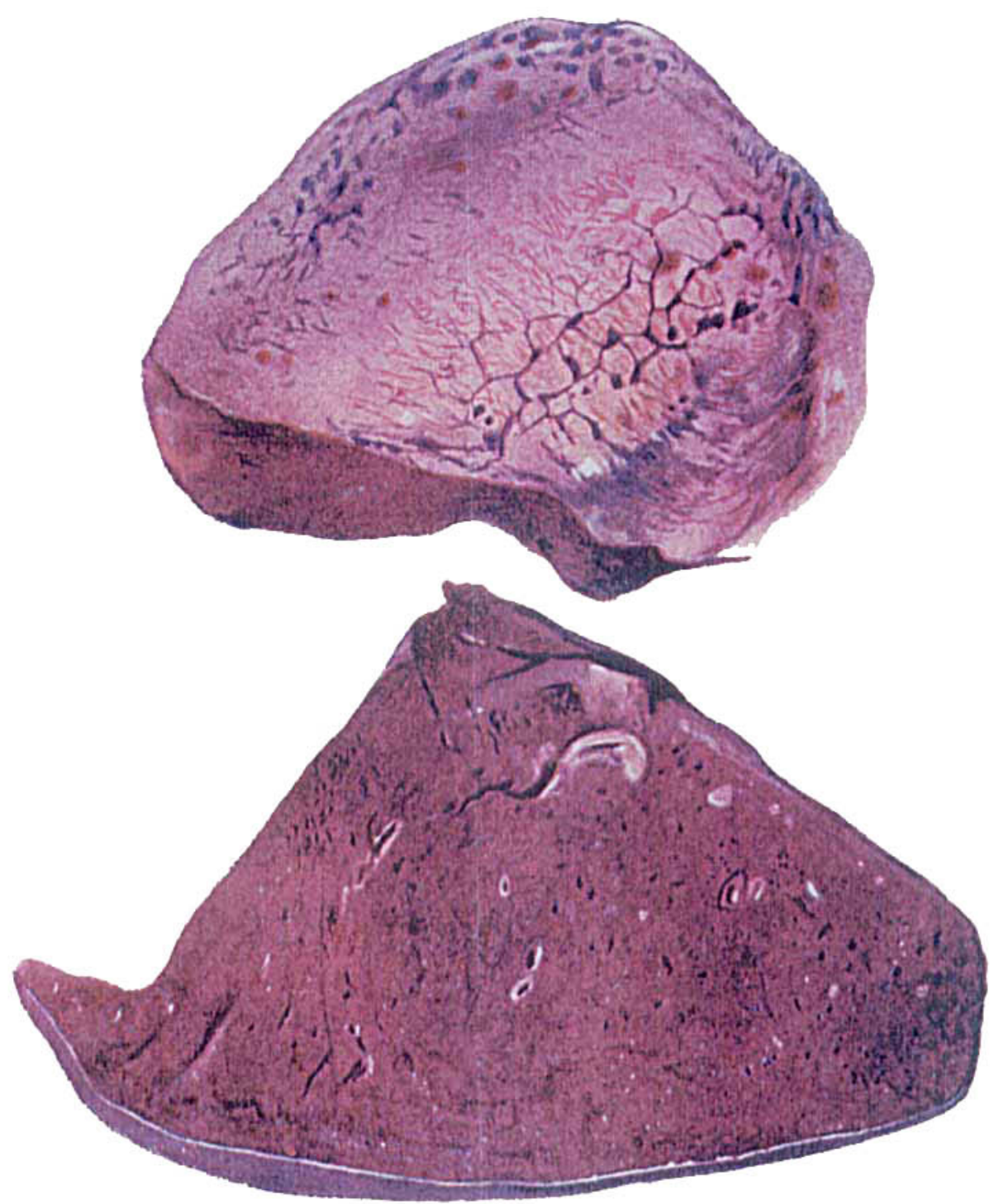

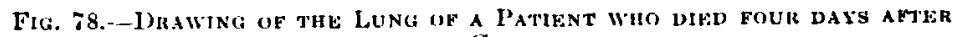
BEINU GASSED. 


\section{THE BRITISH JOURNAL OF SURGERY}

only with the two groups of cases which died of acute asphyxia or of late inflammatory complications.

Immediately after death cases which have died within a few hours or days of being gassed show varying amounts of a very fine froth exuding from both mouth and nose. It may persist for some hours, is distinctly yellow in colour, and imparts a canary yellow tint to fabrics with which it comes into contact. As it subsides, it pigments the skin, so that there is produced a yellow discoloration of varying intensity of the face, more particularly of the lips, the ale nasi, and the inner aspect of the cheeks. Later, post-mortem mottling develops, but it is in no wise different from that which is seen in other cases, either in respect of the time of its onset or in its distribution.

On opening the thorax, the superficial veins are found to be greatly engorged with blood that has clotted early, and the museles are of a deep dullpurple tint. There is frequently emphysema of the anterior.mediastinal tissues, and this condition may spread thence to the loose cellular tissues of the neck, so that they become crepitant.

The pericardial fluid is often increased in amount, and may be bloody. There are often present hæmorrhages of varying extent under the epicardium, particularly towards the base of the heart. The heart itself is intensely engorged throughout all its cavities, and small irregular hæmorrhages may be found under the ventricular endocardium. In one instance of death after twelve days, where there was extensive pulmonary infarction, pale antemortem thrombi were found in both auricle and ventricle.

The changes in the upper respiratory passages, as in the lungs, vary greatly according to the time the case has lived after gassing, and also according to the degree of protection afforded by different types of respirators. Wherc acute irritative changes are developed in full measure, both pharynx and larynx show a deep dull-purple mucous membrane with much-dilated submucons venules (Fig. 75). There may be ocdema about the base of the tongue, round the pillars of the fauces, and in the thyrohyoid lacunæ. In onc case there was found marked blackening of the dorsum of the tongue, while the lymphoid patches at its base, much swollen and reddened, showed numerous punctiform ulecrs. But these appearances are probably of doubtful relationship with the general condition. Inflammatory changes vary considerably in their distribution. For instance, they may be much in evidence at the lower end of the trachea and in the bronchi, while the larynx itself may be quite clear. No case has presented hæmorrhages into the submucosa or into the peribronchial tissues, nor has any condition resembling membrane formation been seen. In carly cases the lumen of the trachea and bronchi is occupicd by a thin frothy serous fluid, which may be blood-stained, and which may be present in such a large amount that the individual can well be said to have drowned in his own oedema fluid. In later cases this thin scrous fluid becomes viscid, tenacious, and mucopurulent.

The pleural fluid may be increased in amount, either from escape of œdema fluid into the cavity, or from inflammatory effusion due to secondary invasion from micro-organisms. The lungs are abnormally large and voluminous, showing but little tendency to collapse on removal from the chest. On the external aspect may be found numerous subpleural hæmorrhages, varying 
much in size and in distribution, but more frequent perhaps along the free margins (Fig. 78), at the posterior surface, and on the internal lobar surfaces. Adjacent hæmorrhages may coalesce, so that the pleura is stripped up over a considerable area and separated from the adjacent lung tissue by a collection of bloody fluid. There is often to be found, too, on the external surface, evidence of ill-defined patches of collapse, alternating with patches of emphysema and with irregular areas of consolidation, the latter frequently with lymph on their pleural surfaces. Intervesicular emphysema, with rows of air-bubbles running in tortuous channels under the pleural surface, is not infrequent.

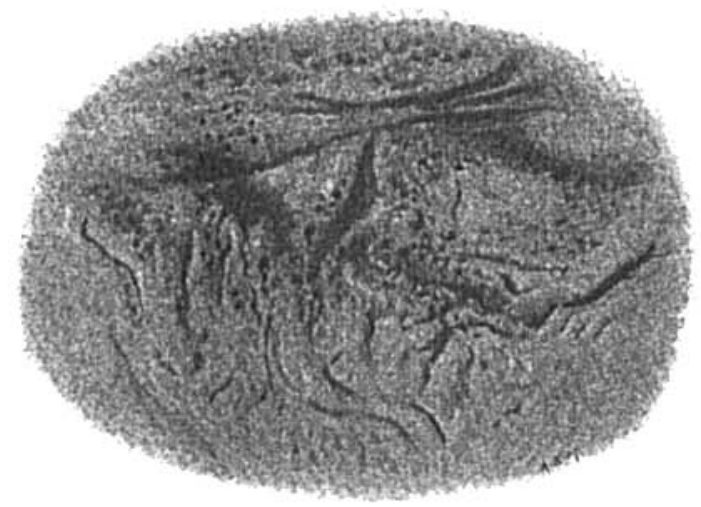

Fig. 79.-Inner surface of the stomach of a patient who died with diffuse bronchopneumonia ten days after exposure to trench gas. Numerous petechiæ are seen, and the stomach' contents were mixed with blood, but there was no actual ulceration. Slight uræmic twitchings developed in this man the day before death, and his kidneys provided the example of nephritis which is described in detail by Lieut. Henry. [Ref. No. 4.]

On section, the lungs in early stages show intense vascular engorgement, and exhibit newly-formed patches of bronchopneumonic consolidation alternating with irregularly scattered areas of emphysema, the latter being just as frequent in the interior of the lung as on the free surface. But superadded to all these changes, and indeed the dominant feature of the whole condition, is an intense oedema, and it is perhaps this appearance more than any other which must be looked on as characteristic. Later, the odema tends to subside, while the small indefinite plum-coloured areas of consolidation coalesce and become more well-defined greyish-yellow patches of bronchopneumonic consolidation. Large pieces of lung, when placed in water, float just level with the surface of the fluid, but it is easy to dissect out pieces which 


\section{THE BRITISH JOURNAL OF SURGERY}

sink completely. Also, there are found at times lung infarctions of moderate size ; or there may be produced a uniform consolidation resulting in complete hepatization. According to information received from the French GasPoisoning Commission, one case at Calais developed lung gangrene at the end of three weeks.

Broadly speaking, odema of the lungs with asphyxial signs is characteristic of the earlier stages of the condition, whereas in the later cases bronchopneumonic and pneumonic consolidation are more in evidence.

The stomach often shows submucous hæmorrhages, limited it may be to the cardiac and to the pyloric end, but often diffusely scattered over the whole viscus. Hæmorrhages may be so extensive that the stcmach and duodenum are filled with black digested blood.

The spleen is enlarged, hard, and firm. Early on, the liver is enlarged, friable, and full of blood, but it soon develops the nutmeg appearance due to prolonged passive hyperæmia.

The change of most interest, perhaps, in the abdominal organs is that which occurs in the kidneys. Kidneys obtained from early cases show nothing more to the naked eye than intense cyanosis, but there is microscopic evidence that such a kidney may show early nephritic changes. In at least one case, and probably to a lesser degree in others, these changes had progressed so far as to give the complete picture of an acute nephritis. The kidney of the patient referred to in the description of Fig. 79 (death after ten days) may be thus described: It is enlarged and pale in colour; the stellate veins are prominent; the capsule is thin, tense, and strips easily. On section, the cortex is of a dull greyish-pink colour, much wider than normal, and its striations are indistinct, while seattered throughout are small brownish-red points showing the position of some of the glomeruli. The intermediate zone is of a greyish colour, and the pyramids are paler than normal. Microscopically, it shows intense nephritis involving both the glomeruli and the tubules. 